\title{
ANALISIS PERANAN WANITA PADA RANTAI NILAI PRODUK TUNA-CAKALANG ASAP DI KOTA BITUNG PROVINSI SULAWESI UTARA
}

\author{
Kristi M.R. Lambaniga'; Alvon Jusuf² ; Vonne Lumenta ${ }^{2}$ \\ 1) Mahasiswa Fakultas Perikanan dan IImu Kelautan Universitas Sam Ratulangi, Manado. \\ 2) Staff Pengajar Fakultas Perikanan dan IImu Kelautan Universitas Sam Ratulangi, Manado. \\ Koresponden email: kristilambaniga@gmail.com
}

\begin{abstract}
Women are important component in fisheries economic development, especially in fisheries value chain. This research aims to know the women's role in the value chain of smoked skipjack-tuna products in Bitung City, North Sulawesi Province. Aspects that were studied include the profile of activities, the profile of access and control, factors that affect the roles of women, as well as the constraints faced by women in exercising their role.

The method used in this research is case study with a focus on the women fish processors of smoked skipjack-tuna in kampung Loyang, Kelurahan Girian Atas, Bitung City. Samples were taken by purposive sampling method and data collection was performed by methods of non-participant observation, interviews, and documentation. Data analysis was carried out using qualitative and quantitative descriptive analysis.

The results of this research showed that the role of women in the value chain of smoked skipjack-tuna products includes conducting sales transaction and bookkeeping, and preparing food for workers, while purchasing of fish as raw materials and other supplementary materials were conducted jointly with men. Women also sell products to market, organize and manage business finance, and control fish processing performed by men. These women's role is supported by several factors, namely, the productive average age, sufficient work experience, small number of family dependents, high job skills, adequate level of education, good social interaction, capital availability and the availability of workers living around the women's business location. Constraints faced by women in this business were the inability to perform heavy physical activities as well as harsh business competition.
\end{abstract}

Key words: the role of women, the value chain, smoked skipjack-tuna

\begin{abstract}
Abstrak
Wanita merupakan komponen penting dalam pembangunan ekonomi perikanan, terutama pada rantai nilai perikanan. Penelitian ini bertujuan untuk mengetahui peranan wanita pada rantai nilai produk tuna-cakalang asap di Kota Bitung Provinsi Sulawesi Utara. Aspek-aspek yang diteliti mencakup profil aktivitas, profil akses dan kontrol, faktor-faktor yang mempengaruhi peranan wanita, serta kendala-kendala yang dihadapi wanita dalam melaksanakan peranannya.

Metode yang digunakan dalam penelitian ini adalah studi kasus dengan fokus pada wanita pengolah produk tunacakalang asap di kampung Loyang, Kelurahan Girian Atas, Kota Bitung. Sampel diambil dengan menggunakan metode purposive sampling dan pengumpulan data dilakukan dengan non participant observation, wawancara dan dokumentasi. Data dianalisis menggunakan analisis deskriptif kualitatif dan analisis deskriptif kuantitatif.

Hasil penelitian ini menunjukkan bahwa peranan wanita dalam rantai nilai produk tuna-cakalang asap meliputi: melakukan transaksi penjualan dan pembukuan, dan menyiapkan makanan untuk pekerja, sementara pembelian ikan sebagai bahan baku dan bahan pelengkap lainnya dilakukan bersamaan dengan laki-laki. Wanita juga menjual produk ke pasar, mengatur dan mengelola keuangan bisnis, dan mengontrol pengolahan ikan yang dilakukan oleh laki-laki. Peranan wanita pada rantai nilai produk tuna-cakalang asap didukung oleh beberapa faktor, yaitu rata-rata usia yang produktif, pengalaman kerja yang cukup, jumlah tanggungan keluarga yang kecil, keterampilan kerja yang tinggi, tingkat pendidikan yang memadai, interaksi sosial yang baik, ketersediaan modal dan keberadaan tenaga kerja pria di sekitar lokasi usaha wanita. Kendala-kendala yang dihadapi wanita adalah ketidakmampuan melakukan kegiatan fisik yang berat serta tingkat persaingan usaha yang sangat ketat.
\end{abstract}

Kata kunci : peranan wanita, rantai nilai, tuna-cakalang asap

\section{PENDAHULUAN}

Wanita merupakan komponen penting dalam pembangunan ekonomi perikanan Indonesia karena memiliki posisi strategis, khususnya dalam rantai nilai perikanan. Sistem rantai nilai mempengaruhi keberlanjutan kegiatan perikanan mulai dari penangkapan ikan di laut, diversifikasi produk oleh pengolah atau industri pengolahan, distribusi produk, serta pemasarannya hingga produk sampai ke tangan 
konsumen lokal maupun luar negeri (Supriatna, dkk. 2014).

Pada aktivitas rantai nilai perikanan, wanita berperan sebagai pedagang pengecer, pengumpul ikan, pedagang besar, buruh upahan, maupun tenaga pengolah hasil perikanan hingga pada proses pemasaran. Namun berbagai aspek kajian ataupun programprogram pembangunan tidak banyak melibatkan wanita. Wanita merupakan sosok penting dalam pembangunan di bidang perikanan dan kelautan (KMIP UGM, 2014).

Provinsi Sulawesi Utara merupakan daerah penghasil dan pengekspor ikan dan Kota Bitung merupakan sentra industrinya. Secara umum, lokasi geografis Kota Bitung tergolong strategis sehingga ditetapkan sebagai pusat kawasan industri Sulawesi Utara (Sompie, 2014).

Ikan tuna-cakalang asap

merupakan industri pengolahan tradisional yang terbagi menjadi usaha kecil dan menengah tersebar pada berbagai wilayah di Kota Bitung. Perikanan tuna-cakalang secara tradisional merupakan industri yang di dominasi oleh laki-laki namun demikian studi literatur dan observasi menunjukan bahwa wanita banyak terlibat dalam beberapa node pada rantai nilai tunacakalang. Analisis peranan wanita menjadi penting untuk melihat nuansa secara keseluruhan dalam industri ini dipengaruhi oleh perbedaan gender sepanjang rantai nilai. Analisis peranan wanita lebih lanjut perlu dilakukan untuk melihat keberagaman dan aktivitas peranan wanita pada sektor industri perikanan. Isu-isu yang membatasi kesetaraan gender dan pemberdayaan wanita perlu ditentukan melalui penelitian ini.

\section{METODOLOGI PENELITIAN}

Metode yang digunakan dalam penelitian ini adalah pendekatan studi kasus. Studi kasus adalah metode penelitian yang dilakukan dengan cara menjadikan objek penelitian sebagai suatu kasus yang perlu diteliti dan dianalisis secara detail sampai tuntas.

Data yang dikumpulkan berasal dari berbagai sumber hasil penelitian yang berkaitan dengan kasus yang diteliti terdiri dari data primer dan data sekunder. Pengambilan sampel dilakukan dengan purposive sampling. Metode pengumpulan data dalam penelitian adalah non participant observation (obervasi tidak berperan serta), wawancara, metode harvard dan dokumentasi.

Metode analisis data yang digunakan adalah analisis deskriptif kualitatif dan analisis deskripstif kuantitatif. 
HASIL DAN PEMBAHASAN

Profil Aktifitas

Kegiatan produktif

Tabel. Kegiatan Produktif pada Rantai Nilai Produk Tuna-Cakalang asap

\begin{tabular}{|c|c|c|c|}
\hline Kegiatan Produktif & Pria & Wanita & Bersama \\
\hline \multicolumn{4}{|c|}{ Pendaratan ikan di PPI } \\
\hline $\begin{array}{l}\text { Mengangkut ikan dari } \\
\text { kapal ke darat }\end{array}$ & $\sqrt{ }$ & & \\
\hline $\begin{array}{l}\text { Memecahkan dan memberi } \\
\text { es pada ikan }\end{array}$ & & & $\sqrt{ }$ \\
\hline Transaksi penjualan & & $\sqrt{ }$ & \\
\hline Membuat pembukuan & & $\sqrt{ }$ & \\
\hline \multicolumn{4}{|c|}{ Pengolahan } \\
\hline Memberikan penanganan awal & $\sqrt{ }$ & & \\
\hline $\begin{array}{l}\text { Membersihkan dan mengeluarkan } \\
\text { bagian dalam ikan }\end{array}$ & $\sqrt{ }$ & & \\
\hline Membelahan ikan menjadi dua bagian & $\sqrt{ }$ & & \\
\hline Menjepit ikan dengan bambu & $\sqrt{ }$ & & \\
\hline Mewarnai ikan & $\sqrt{ }$ & & \\
\hline Mengatur ikan di tungku pengasapan & $\sqrt{ }$ & & \\
\hline Pengasapan & $\sqrt{ }$ & & \\
\hline $\begin{array}{l}\text { Mengatur keuangan } \\
\text { Pengolahan }\end{array}$ & & $\sqrt{ }$ & \\
\hline \multicolumn{4}{|c|}{ Penjualan } \\
\hline Menjual (pasar, kios/warung) & & $\sqrt{ }$ & \\
\hline Mendistribusikan (pedagang, konsumen) & & & $\sqrt{ }$ \\
\hline Mengatur keuangan hasil penjualan & & $\sqrt{ }$ & \\
\hline
\end{tabular}

Sumber : Data primer, diolah Juni 2017

Pengangkutan ikan ke darat dan penghancuran es dilakukan oleh pria karena dibutuhkan tenaga yang kuat untuk membawa ikan-ikan tersebut dalam keranjang, ember maupun coolbox. Sedangkan wanita melakukan penjualan dan melakukan transaksi agar dapat di menghitung untung-rugi yang dihasilkan pada hari itu. Biasanya jika es yang akan di gunakan bentuknya kecil maka wanita yang bisa melakukannya. Aktvitas pengolahan ikan tuna-cakalang asap lebih banyak dilakukan oleh pria dan wanita biasanya memberi warna pada ikan, mengatur pendapatan dan pengeluaran usaha serta mengatur keuangan dalam proses pengolahan tersebut.

Pendapatan tergantung banyaknya produksi dan ukuran ikan, untuk produksi $100 \mathrm{~kg}$ ikan dengan harga produk $\mathrm{Rp} 50.000$,- per jepit berkisar Rp Rp 2.182.000. Keuntungan tersebut merupakan hasil dari penjualan di pasar yang telah dikurangi dari keseluruhan pengeluaran. 


\section{Kegiatan Reproduktif}

Tabel. Kegiatan Reproduktif Pada Rantai Nilai Produk Tuna-Cakalang Asap

\begin{tabular}{|c|c|c|c|}
\hline Reproduktif & Pria & Wanita & Bersama \\
\hline \multicolumn{4}{|c|}{ Reproduktif di PPI } \\
\hline Menyediakan ember, keranjang dan coolbox & & & $\sqrt{ }$ \\
\hline Menyediakan es & $\sqrt{ }$ & & \\
\hline Menyediakan kendaraan pengangkut & $\sqrt{ }$ & & \\
\hline \multicolumn{4}{|c|}{ Reproduktif di pengolahan } \\
\hline $\begin{array}{l}\text { Membersihkan peralatan dan } \\
\text { perlengkapan pengolahan }\end{array}$ & $\sqrt{ }$ & & \\
\hline $\begin{array}{l}\text { Merawat/memperbaiki peralatan } \\
\text { dan perlengkapan yang rusak }\end{array}$ & $\sqrt{ }$ & & \\
\hline Membersihkan tempat pengolahan & $\sqrt{ }$ & & \\
\hline Memasak dan menyiapkan makanan tenaga kerja & & $\sqrt{ }$ & \\
\hline Membeli bahan baku/ikan dan bahan tambahan lainnya & & & $\sqrt{ }$ \\
\hline Membeli peralatan dan perlengkapan pengolahan & & & $\sqrt{ }$ \\
\hline Mengelola keuangan usaha pengolahan & & $\sqrt{ }$ & \\
\hline \multicolumn{4}{|c|}{ Reproduktif di penjualan } \\
\hline Menyediakan kendaraan angkutan & & $\sqrt{ }$ & \\
\hline Menyewa tempat berjualan & & $\sqrt{ }$ & \\
\hline
\end{tabular}

Sumber : Data primer, diolah Juni 2017

Kegiatan reproduktif yang dilakukan adalah menyediakan keranjang, ember dan coolbox dilakukan secara bersama-sama oleh pria dan wanita sedangkan menyediakan es dan menyediakan kendaraan pengangkutan dari PPI ke pengolah hanya dilakukan oleh pria. Aktivitas kerja pengolahan dilakukan oleh sebagian besar pria sebagai pekerja namun wanita menyiapkan makanan tenaga kerja dan untuk pembelian bahan baku ikan, bahan tambahannya lainya seperti pewarna makanan, sabut kelapa, serta perlengkapan dan peralatan pengolahan dilakukan bersama. Penjualan hanya dilakukan oleh para wanita sehingga pada kegiatan reproduktif ini wanita yang paling berperan mengatur proses penjualan.

\section{Kegiatan Sosial}

Tabel. Kegiatan Sosial Pada Rantai Nilai Produk Tuna-Cakalang Asap

\begin{tabular}{|c|c|c|c|}
\hline Kegiatan Sosial & Pria & Wanita & Bersama \\
\hline Mengikuti kelompok arisan & & $\sqrt{ }$ & \\
\hline Mengikuti kelompok usaha & & $\sqrt{ }$ & \\
\hline Gotong royong & & & $\sqrt{ }$ \\
\hline Menghadiri acara perayaan dan duka & & & $\sqrt{ }$ \\
\hline
\end{tabular}

Sumber : Data primer, diolah Juni 2017

Hubungan sosial yang baik antara pemilik maupun pekerja, penjual dan pembeli, sesama pelaku usaha baik sebagai nelayan, pedagang perantara, pedagang besar, pedagang kecil, petibo dan pengolah sangat mempengaruhi hubungan kerja sama yang terus berkelanjutan agar usaha yang dijalankan terus bergerak dan berkembang. Salah satu kegiatan sosial yang juga dilakukan yaitu dengan membentuk suatu kelompok usaha pada pengolahan ikan asap. 


\section{Profil Akses dan Kontrol}

\section{Partisipasi Kuantitatif}

Partisipasi kuantitatif merupakan suatu alat ukur yang digunakan untuk mengetahui seberapa besar peran wanita dalam kegiatan tertentu dan tugas apa saja.

Tabel. Akses Pada Rantai Nilai Tuna-Cakalang Asap

\begin{tabular}{|c|c|c|c|}
\hline Sumber daya & Pria & Wanita & Bersama \\
\hline \multicolumn{4}{|c|}{ Sumber fisik/material } \\
\hline Ember, loyang, coolbox & & & $\sqrt{ }$ \\
\hline Kendaraan pengangkut ke pengolah & & & $\sqrt{ }$ \\
\hline Pembelian bahan baku dan bahan tambahan lainnya & & & $\sqrt{ }$ \\
\hline Kebersihan lokasi, peralatan dan perlengkapan pengolahan & $\sqrt{ }$ & & \\
\hline Kendaraan pendistribusian ke pasar & & & $\sqrt{ }$ \\
\hline Waktu penjualan & & $\sqrt{ }$ & \\
\hline Harga jual & & $\sqrt{ }$ & \\
\hline Kebersihan lokasi penjualan & & $\sqrt{ }$ & \\
\hline Pengelolaan keuangan pengolahan & & $\sqrt{ }$ & \\
\hline Pengelolaan keuangan penjualan & & $\sqrt{ }$ & \\
\hline \multicolumn{4}{|c|}{ Sumber daya sosial budaya } \\
\hline Pendidikan & & & $\sqrt{ }$ \\
\hline Penyuluhan perikanan (pengolahan dan penjualan) & & & $\sqrt{ }$ \\
\hline Strategi pengelolaan usaha & & & $\sqrt{ }$ \\
\hline \multicolumn{4}{|c|}{ Manfaat } \\
\hline Hasil penjualan produk tuna-cakalang asap & & & $\sqrt{ }$ \\
\hline Pemegang pendapatan hasil penjualan & & $\sqrt{ }$ & \\
\hline
\end{tabular}

Sumber : Data primer, diolah Juni 2017

Umumnya di PPI didominasi oleh pria yang mengerjakan pekerjaan berat seperti mengangkut ikan dari atas kapal ke darat bahkan sampai ke mobil para petibo, pemecahan es balok agar tetap terjaga kualitas ikan yang segar sedangkan para wanita melakukan pekerjaan yang lebih mudah yaitu melakukan transaksi menjual dan membeli ikan serta bagian administrasi pembukuan. Usaha pengolahan lebih banyak dilakukan oleh para pria yang bekerja melakukan proses pengolahan dan tugas wanita adalah hanya menjual produk ikan tuna-cakalang asap di pasar dan mengatur keuangan usaha dan wanita juga mengamati produk dalam proses pengasapan agar suhu tetap terjaga sehingga menghasilkan produk yang baik untuk dipasarkan.

\section{Partisipasi Kualitatif}

Partisipasi kualitatif adalah bagaimana peran wanita dalam kontrol pengambilan keputusan.

Tabel. Kontrol Pada Rantai Nilai Tuna-Cakalang Asap

\begin{tabular}{|l|l|c|c|}
\hline \multicolumn{1}{|c|}{ Sumber daya } & \multicolumn{1}{c|}{ Pria } & Wanita & Bersama \\
\hline \multicolumn{1}{|c|}{ Sumber daya fisik/material } & & $\sqrt{ }$ \\
\hline Ember, loyang, coolbox & & & $\sqrt{ }$ \\
\hline Kendaraan pengangkut & & & $\sqrt{ }$ \\
\hline Pembelian bahan baku dan bahan tambahan lainnya & & & $\sqrt{ }$ \\
\hline Kebersihan lokasi, peralatan dan perlengkapan pengolahan & & & $\sqrt{ }$ \\
\hline Kendaraan pendistribusian & & $\sqrt{ }$ & \\
\hline Waktu penjualan & & $\sqrt{ }$ & \\
\hline Harga jual & & $\sqrt{ }$ \\
\hline
\end{tabular}




\begin{tabular}{|c|c|c|c|}
\hline Sumber daya & Pria & Wanita & Bersama \\
\hline Kebersihan lokasi penjualan & & $\sqrt{ }$ & \\
\hline Pengelolaan keuangan pengolahan & & $\sqrt{ }$ & \\
\hline Pengelolaan keuangan penjualan & & $\sqrt{ }$ & \\
\hline \multicolumn{4}{|c|}{ Sumber daya sosial budaya } \\
\hline Pendidikan & & & $\sqrt{ }$ \\
\hline $\begin{array}{l}\text { Penyuluhan perikanan } \\
\text { (pengolahan dan penjualan) }\end{array}$ & & $\sqrt{ }$ & \\
\hline Strategi pengelolaan usaha & & & $\sqrt{ }$ \\
\hline \multicolumn{4}{|c|}{ Manfaat } \\
\hline Hasil penjualan produk tuna-cakalang asap & & $\sqrt{ }$ & \\
\hline Pemegang pendapatan hasil Penjualan & & $\sqrt{ }$ & \\
\hline
\end{tabular}

Sumber : Data primer, diolah Juni 2017

Peran wanita dalam pengambilan keputusan pada setiap rantai nilai beragam, pada pendaratan ikan di PPI wanita mengontrol transaksi penjualan dan pembelian ikan. Wanita pedagang besar, pedagang kecil, pedagang perantara hingga petibo melakukan tawar menawar harga ikan. Wanita pada usaha pengolahan ini tidak hanya berperan sebagai pemilik usaha juga menjual produk tuna-cakalang asap.

\section{Fungsi Pendukung}

Umur

Berdasarkan umur responden dengan kisaran usia 15-55 tahun menunjukkan usia yang produktif sehingga tidak menghambat aktivitas kerja wanita dan menjadi suatu faktor pendukung dalam proses produksi usaha tuna-cakalang asap.

\section{Lama Kerja}

Berdasarkan responden wanita jumlah terbanyak dengan lama kerja $>10$ tahun sebanyak 9 orang menunjukkan semakin lama seseorang bekerja maka semakin memiliki keterikatan hubungan atau semakin merasa memilki terhadap lingkungan. Wanita dengan pengalaman kerja yang telah mencapai $>10$ tahun berarti telah memiliki keterikatan hubungan yang sangat baik dengan lingkungannya, selain itu pekerjaan tersebut berarti sangat membantu dalam memenuhi kebutuhan rumah tangga.

\section{Pendidikan}

Berdasarkan responden wanita dengan tingkat pendidikan SD terbanyak berjumlah 6 orang menunjukkan tingkat pendidikan menjadi peluang untuk kesempatan kerja tanpa menjadi hambatan dengan mengetahui proses kerja yaitu dengan cara pelatihan. Mengolah ikan asap tidak diperlukan pendidikan yang tinggi tetapi dengan belajar sendiri melihat dan mempelajari cara kerja dalam bentuk pelatihan sehingga akan terbentuk keahlian, keterampilan dan pengalaman kerja yang baik di dukung dengan modal dan tenaga kerja agar usaha dapat berjalan dan berkembang.

\section{Jumlah Tanggungan Keluarga}

Berdasarkan responden wanita dengan jumlah tanggungan keluarga terbanyak 1-2 berjumlah 9 orang. Semakin banyak jumlah tanggungan keluarga maka akan semakin banyak pula kebutuhan rumah tangga. Sehingga untuk memenuhi kebutuhan anggota keluarga maka baik pria dan wanita keduanya bekerja dengan giat. Wanita bekerja agar dapat membantu memenuhi semua kebutuhan anggota keluarga. 


\section{Pendapatan}

Pendapatan yang diperoleh wanita dari hasil penjualan produk tunacakalang asap sangat mempengaruhi ekonomi rumah tangga untuk memenuhi kebutuhan keluarga. Selain untuk kebutuhan anggota keluarga hasil penjualan juga digunakan untuk mengelola usaha agar terus dapat melakukan pengolahan ikan tunacakalang asap. Banyaknya produksi mempengaruhi banyaknya produk yang dijual sehingga pendapatan yang diperoleh meningkat.

\section{Keterampilan Kerja}

Keterampilan kerja merupakan kemampuan seseorang untuk melakukan pekerjaan dalam bidangnya khusus pada pengolahan tuna-cakalang asap, wanita terampil dalam memilih ikan yang segar dan baik untuk diolah dibandingkan dengan pria. Keterampilan kerja dapat di pelajari melalui pelatihan dan lamanya seseorang bekerja melakukan hal tersebut. Keterampilan kerja mempengaruhi hasil produk yang berkualitas sehingga wanita sangat berperan dalam pemilihan ikan yang akan diolah. Wanita juga terampil dalam menjual produk tuna-cakalang asap karena mereka lebih aktif dalam mempromosikan produk jualannya.

\section{Interaksi Sosial}

Semakin baik suatu hubungan kerja maka kerja sama yang baik akan terus berkelanjutan, akan tetapi jika kurangnya interaksi maka dalam melakukan kerja akan banyak terjadi perselisihan atau salah paham. Wanita sangat mempengaruhi hubungannya dengan orang lain sehingga terjalin interaksi sosial yang akrab. Hubungan yang baik ini terus berkelanjutan baik dalam usaha pengolahan dan penjualan ikan tuna-cakalang asap maupun hubungan sosial bermasyarakat. Salah satu interaksi sosial yang dilakukan wanita yaitu menjadi anggota dalam suatu kelompok usaha, hal ini menunjukan bahwa hubungan yang terjalin baik membentuk suatu perkumpulan yang menjadi sarana untuk dapat membantu para wanita mengelola dan mengembangkan usahanya.

\section{KESIMPULAN}

Dari hasil penelitian ini dapat ditarik beberapa kesimpulan sebagai berikut:

1. Wanita membeli ikan di PPS Bitung tergantung waktu pendaratan ikan. Tempat usaha pengolahan umumnya berada di sebelah rumah, dilakukan selama kurang lebih 8 jam. Penjualan produk tuna-cakalang asap dilakukan pada subuh hingga pagi atau sampai ikan terjual habis. Tujuan penjualan ke pedagang besar serta kepasar lokal di Kota Bitung dan di Kota Manado, yang mencakup titik penjualan di Sario, Pasar Bersehati, Pasar Karombasan, Pasar Paniki, rumah makan, dan konsumen langsung. Pendapatan tergantung banyaknya produksi dan ukuran ikan.

2. Pria melakukan banyak pekerjaan berat dibandingkan wanita. Wanita melakukan transaksi penjualan serta administrasi pembukuan, menyiapkan makanan tenaga kerja dan untuk pembelian bahan baku ikan, bahan tambahannya lainya seperti pewarna makanan, sabut kelapa, serta perlengkapan dan peralatan pengolahan dilakukan bersama. Wanita menjual ikan di pasar dan sebagai pemilik usaha juga berperan mengatur dan mengelola keuangan usaha. 
3. Peranan wanita pada rantai nilai produk tuna-cakalang asap didukung oleh beberapa faktor, yaitu rata-rata usia yang produktif, pengalaman kerja yang cukup, jumlah tanggungan keluarga yang kecil, keterampilan kerja yang tinggi, tingkat pendidikan yang memadai, interaksi sosial yang baik, ketersediaan modal dan keberadaan tenaga kerja pria di sekitar lokasi usaha wanita.

4. Kendala utama yang dihadapi para wanita pada rantai nilai produk tunacakalang asap adalah ketidakmampuan melakukan kegiatan fisik yang berat serta tingkat persaingan usaha yang sangat ketat.

\section{DAFTAR PUSTAKA}

KMIP UGM. 2014. Peran Wanita Nelayan. Kelompok Mahasiswa IImu Perikanan Fakultas Pertanian. Universitas

Gajah

Mada. http://kmip.faperta.ugm.ac.id/peran-wanitanelayan/

Kumbadewi, L.S. Wayan, S. Gede, P.A. 2016. Pengaruh Umur, Pengalaman Kerja, Upah, Teknologi Dan Lingkungan Kerja Terhadap Produktivitas Karyawan. e-Journal BISMA Universitas Pendidikan Ganesha Singaraja, Indonesia. Vol.4. Hal. 9.

Mahendra, A.D. 2014. Analisis Pengaruh Pendidikan, Upah, Jenis Kelamin, Usia Dan Pengalaman Kerja Terhadap Produktivitas Tenaga Kerja (Studi Di Industri Kecil Tempe Di Kota Semarang. Skripsi. Universitas Diponegoro, Semarang. Hal. 9, 40, 44-45.

Setiawan, S.A. 2010. Pengaruh Umur, Pendidikan, Pendapatan, Lama kerja dan Jenis Kelamin, Terhadap Lama Mencari Kerja Bagi Tenaga Kerja Terdidik Di Kota Magelang. Skripsi. Universitas Diponegoro, Semarang. Hal. 25-26.

Sompie, J.G. 2014. Analisis Sumber Daya Perikanan dalam Pembangunan Daerah Kota Bitung. KRITIS, Jurnal Studi Pembagunan Interdisiplin, Vol. XXIII, No 1, hal. 46-63.

Supriatna, A. Hascaryo, B. Wisudo, S.H. Mulyono, B. Nikijuluw, V. 2014. Model Rantai Nilai Pengembangan Perikanan Tuna, Tongkol, Dan Cakalang Di Indonesia. JPHPI, Volume 17 Nomor 2, hal. 144-155. 